\title{
Principles of Tribology
}




\section{Principles of Tribology}

Edited by

\section{J. Halling}

Professor of Engineering Tribology

University of Salford 
(C) The Contributors 1975,1978

All rights reserved. No part of this publication may be reproduced or transmitted, in any form or by any means, without permission.

First edition 1975

Paperback edition 1978

Published by

THE MACMILLAN PRESS LTD

London and Basingstoke

Associated companies in Delhi Dublin

Hong Kong Johannesburg Lagos Melbourne

New York Singapore and Tokyo

ISBN 978-0-333-24686-3 ISBN 978-1-349-04138-1 (eBook)

DOI 10.1007/978-1-349-04138-1

This book is sold subject to the standard conditions of the Net Book Agreement.

The paperback edition of this book is sold subject to the condition that it shall not, by way of trade or otherwise, be lent, resold, hired out, or otherwise circulated without the publisher's prior consent in any form of binding or cover other than that in which it is published and without a similar condition including this condition being imposed on the subsequent purchaser. 
This book is dedicated to the Lima Arms whose efficacious personal lubrication service has often eased the path to its completion 


\section{Contents}

Foreword

Preface

xi

xiii

1 Introduction

J. Halling

1.1 Tribology

1.2 Historical

1.3 Tribology in industry

1.4 Economic considerations

1.5 Tribological solutions

2 Surface Properties and Measurement

J. Halling and $K$. A. Nuri

2.1 The nature of metal surfaces

2.2 Surface texture assessment

2.3 Surface parameters

2.4 The statistical properties of surfaces

2.5 Measurement of surface parameters

3 Contact of Surfaces

40

J. Halling and K. A. Nuri

3.1 Introduction

3.2 Stress distribution due to loading

3.3 Displacements due to loading 
3.4 Hertzian contacts $\quad 48$

3.5 The contact of rough surfaces 61

3.6 Criterion of deformation mode 65

$\begin{array}{lll}3.7 & \text { Thermal effects } & 67\end{array}$

4 Friction Theories 72

$\begin{array}{lll}4.1 & \text { Introduction } & 72\end{array}$

4.2 Friction measurement 74

4.3 Possible causes of friction 77

4.4 The adhesion theory of friction $\quad 79$

4.5 Modified adhesion theory 81

4.6 Plastic interaction of surface asperities 87

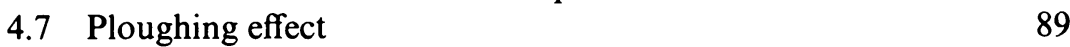

4.8 Elastic hysteresis losses 91

4.9 Discussion of the various friction theories 91

5 Wear 94

D. G. Teer and R. D. Arnell

5.1 Introduction 94

5.2 Types of wear 95

5.3 Various factors affecting wear 113

$\begin{array}{ll}5.4 \text { Experimental aspects } & 120\end{array}$

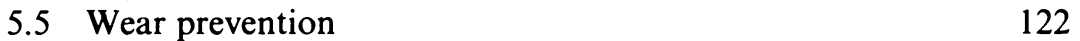

5.6 Application of wear relationships to design 122

5.7 An example of wear in practice - wear of an i.c. engine 125

5.8 Conclusions 126

6 Tribological Properties of Solid Materials 128

R. D. Arnell and D. G. Teer
6.1 Introduction
128
6.2 Tribological properties of metals
129
6.3 Self-lubricating materials
6.4 Types of solid lubricant
6.5 Tribological properties of plastics

7 Friction Instability

7.1 Introdüction

7.2 Characteristics of friction vibrations 151

7.3 Review of analytical methods 154

$\begin{array}{lll}7.4 & \text { Frictional force models } & 158\end{array}$ 
7.5 Analysis of stick-slip oscillations

7.6 Further analysis

7.7 Elimination of stick-slip

8 Mechanics of Rolling Motion

174

J. Halling
8.1 Introduction
174
8.2 Free rolling
175
8.3 Microslip in rolling
184
8.4 Tyre-road contacts
198

9 Lubricant Properties and Testing

202

R. B. Howarth

$\begin{array}{lll}9.1 & \text { Introduction } & 202 \\ 9.2 & \text { Viscosity } & 202 \\ 9.3 & \text { Measurement of viscosity } & 213 \\ 9.4 & \text { Lubricating oils } & 224 \\ 9.5 & \text { Greases } & 228\end{array}$

10 Hydrodynamic Lubrication 233

T. L. Whomes

10.1 Introduction 233

10.2 Theory 235

10.3 Application of Reynolds equation to sliding bearings 238

10.4 Contacts in the form of non-conforming discs 243

$\begin{array}{ll}10.5 & \text { The journal bearing } \\ 10.6 & 247\end{array}$

10.6 Variable viscosity - the reduced pressure concept 252

10.7 Shear stresses and traction in hydrodynamic films 254

10.8 Finite length bearings 260

10.9 Thermal effects 268

10.10 Gas-lubricated bearings $\quad 271$

10.11 Hydrodynamic instability 282

11 Elastohydrodynamic Lubrication 288

T. L. Whomes and J. Halling

11.1 Highly loaded contacts 288

11.2 Elastohydrodynamic theory 291

11.3 Comparison of theory and experiment 296

11.4 Traction 300

11.5 Three-dimensional solutions 304

11.6 Fatigue failure 306 
12.1 Externally pressurised bearings 308

12.2 General description of hydrostatic bearings 309

12.3 Viscous flow through rectangular gaps and circular tubes

12.4 Long rectangular thrust bearings in constant flow system

12.5 The need for compensation in multibearing arrangements

12.6 Characteristics of compensated bearings 317

12.7 Comparison of characteristics 325

12.8 Flow, load and power factors for other shapes of bearings

12.9 Sliding effects in thrust bearings 340

12.10 Hydrostatic journal bearings 349

12.11 Other types of hydrostatic bearings 358

13 Selection of tribological solutions 360

13.1 Introduction 360

13.2 Load and speed 361

$\begin{array}{ll}\text { 13.3 The selection of journal bearings } & 367\end{array}$

13.4 Matching of tribological solutions 367

13.5 Conclusions 368

$\begin{array}{ll}\text { Appendix A } & 369\end{array}$

$\begin{array}{ll}\text { Appendix B } & 375\end{array}$

Author Index 394

$\begin{array}{ll}\text { Subject Index } & 397\end{array}$ 


\section{Foreword}

by H. Peter Jost

Chairman: Committee on Tribology, Department of Industry, 1966-74

President: International Tribology Council

Without tribology, in other words, without 'interacting surfaces in relative motion', that is, surfaces rolling on each other, surfaces sliding over each other and surfaces rubbing on each other, life would be impossible.

This truism applies equally to heavy machinery and to a precision mechanism; to a brake and to a rocket; to a mechanical and to a human joint.

Friction and wear, the principal constituents of tribology, have been with us since time immemorial, so have been our efforts to control the former and minimise the latter. However, it is only less than nine years ago, that the modern interdisciplinary concept of tribology was recognised in the United Kingdom, since when its progress has spread like wildfire throughout the industrial world.

The main reason behind this development, which is also the principal reason for the importance of this book, is the recognition of the close interrelationship between tribological design principles and practices on the one hand, and their economic effect on the other. The days of single disciplinary designs and of design by trial and error are gone forever. Modern products must, during their design stages, have incorporated all the factors that lead to a satisfactory control of friction and prevention of wear.

For this to be accomplished, Professor Halling and his co-authors have 
provided, in a single volume, nearly all the basic theory needed for a thorough grounding in the subject. It will therefore be a book most useful for every engineering student; in addition, I believe that Principles of Tribology will be found very useful by practising engineers in industrial design and research departments. For here, the concentration of valuable information in one volume, will eliminate the consultation of several sources of books and scientific papers, a saving of valuable time that will be appreciated by those employed in industry and others working against the clock.

Similarly, this book should be of considerable value to workers in many other fields, whose occupation brings them face to face-often unpleasantly so-with the realities of tribological problems and who may find, in this volume, fundamental answers to at least some of their problems.

The original Report, that bears my name, estimated that by the better application of tribological principles and practices, industry in the United Kingdom could save around $£ 515$ million per annum (at 1965 values). During the years since its publication, it has become apparent that this estimate of savings has been too conservative. Indeed, in a recent Report, commissioned by the Congress of the United States of America, it was stated that there was considerable scope for savings of losses through tribological causes (friction and wear), which were estimated to cost the U.S. economy around $\$ 100$ billion per annum, of which $\$ 20$ billion were in materials.

The savings through the correct application of tribological principles, as outlined in this book, can be considerable. A recent report, commissioned by the S.S.R.C., concluded that 'for individual enterprises-even efficient ones - the rate of return in improvements in the tribological characteristics of their capital equipment could be very high indeed-far higher than is customary on ordinary industrial investments'.

Modern machines, mechanisms and equipment must be reliable. I firmly believe that the application of the ground rules, contained in Principles of Tribology, will materially contribute towards greater reliability of industrial products and therefore to the economy of this country.

I congratulate Professor Halling and his co-authors on their work, which I can warmly recommend not only to those desiring to become engineers, but also to those professional engineers and others whose work is connected with the control of friction and the prevention of wear, in other words, in work where the minimisation of breakdowns, replacements and outages through tribological causes are of importance.

\section{London}

H. PETER JOST 


\section{Preface}

Tribology is a new word, not yet in common usage, but it deals with problems which man has encountered throughout the whole of his history. The word was introduced to focus attention on the problem of carrying load across solid interfaces in relative motion. The ingredients of the subject are therefore well-established batches of knowledge which occur in a wide range of texts on such topics as lubrication, friction, wear, contact mechanics, surface physics, and chemistry. The subject is truly interdisciplinary since the basic knowledge from physics, chemistry, mathematics, materials science and engineering is used to study problems in all branches of engineering, in medicine, and in almost all aspects of our daily life from the cleaning of our teeth to the slicing of our golf drive.

The awareness of the social and economic importance of this subject has resulted in its introduction into several courses at colleges and universities. This book is an attempt to bring together in a single volume those topics which are currently scattered throughout the scientific literature. In particular this volume concentrates on the basic principles of the subject, using practical examples only to demonstrate the physical manifestations of these principles. This book should, therefore, prove a useful supplement to other volumes dealing with such specific practical applications as the design of bearings. The book is basically aimed at the final-year level of undergraduate courses in engineering, but the authors hope that it will prove of interest to a wider readership. Research workers, new to the subject, and designers and development engineers seeking background knowledge to the existing literature should all find the subject matter relevant.

The authors have deliberately excluded illustrations of standard equipment 
and techniques since these should already be familiar to final-year undergraduates and practising engineers. The notation may also appear to lack complete consistency but it has been considered desirable to use that notation which is already well established in the literature concerned with the various topics considered. This should facilitate the use of standard references, many of which are included with each chapter. The symbols used are clearly identified in the text of each chapter.

It may be that the relatively large number of authors has resulted in some variation in literary style, but since each chapter is more or less self-contained this should offer no problem to the reader. Since all the authors belong to the same department we believe that our collaborative efforts have resulted in a coherent philosophy for the book. In each topic the authors have concentrated on the important physical principles and have not thought it desirable to include rigorous development of the mathematical treatment, although the most significant mathematical formulations are included. Since the authors are mainly concerned with the engineering applications of tribology, it will be noted that this book does not include much information on the chemical aspects of tribology. This does not imply any denigration of the importance of such material but rather that such topics tend to be of a rather specialist interest.

The final chapter has been included as an indication of the relevance of the remainder of the book. Indeed this chapter could be taken out of sequence if the reader seeks to appreciate the value of the topics discussed in the various chapters.

A number of problems together with outline solutions have been included in an appendix to this book, since the final proof of assimilation of concepts must be our ability to handle them in given situations.

Finally the authors would like to acknowledge their deep gratitude for the enthusiastic and competent way in which Mrs L. M. Chadderton has transcribed their often untidy drafts into a coherent manuscript. 